\title{
ERFENIS EN ONTWIKKELING IN DIE SUID-AFRIKAANSE INDUSTRIE
}

Erfenis uan produk

Ons erfenis op nywerheidsgebied is in die eerste plek 'n erfenis van "produk". Anders as die Boesmans wat behalwe pyl en boog, kalbas en stertriem weinig benodig, het ons as spruite van die Weste 'n ryke erfenis aan benodigdhede.

Van die oggend vroeg af, wanneer ons uit die bed klim ('n instelling wat die outydse rusbanke vervang het - en die murkasbed van die Middeleeue opgevolg het), ons slaapklere uittrek ('n tipe van Indiese slaappak wat die naghemp van die Weste vervang het) en ons môrestortbad neem ('n Indiese ontdekking hierheen gebring deur die Britte), is ons onderhewig aan allerlei onafwendbare invloede.

Ons eet 'n Skotse pap gevolg deur Engelse spek en eiers en roosterbrood. Ons dra pakke klere afgelei van die baadjies en broeke van die Franse kleremakers uit die Franse Rewolusie. Ons dra hoede van sagte vilt wat in Spanje ontstaan het. Ons eet met vurke - 'n gewoonte wat uit Venesië stam.

Maar hierdie artikels deur ons benodig. moet gefabriseer word.

'n Fabriek is volgens ons Suid-Afrikaanse nywerheidswetgewing ' $n$ werkplek waar drie of meer mense georganiseerd vervaardig.

Nywerheid benodig werkplek, grondstof, arbeid en bowenal hestuur. Dis juis laasgenoemde waarin die onderontwikkelde Afrika-lande so kortskiet.

Erfenis van bestuur

Ons erfenis op nywerheidsgebied is dus 'n erfenis veelnl van ,bestuur" -... dic geskiedenia van menslike organisasie.

\section{Babiloniese}

Dit voer ver terug, sover as die ou beskawings van die 
Midde.Ooste, want die kade van Hammurabi, 2150 v.C., het reeda die hasis gelê vir die besigheidspraktyke van vandag.

Sy 285 wette, wat: in anhef selfs herinner aan dié van vandag, was byna wetenskaplik ingedeel onder honfde soos: personnlike besittings, vaste eiendom, handel, die familie. injuria, arbeid ens. Selfs die seël van 'n regskontrak met 'n amptelike seël dateer uit die dae van Hammurabi.

Hierdie vroeë kode het die landbou gestimulcer en handel en nywerheid bevorder. En reeds toe was die nywerheid yeorganiseer in gildes of stamme. met meesters en leerlinge.

\section{Hebreeuse}

Uit die Hebreeuse beskawing kry ons die eerste rekord ian die filosofie en plan van organisasie en wel in Exodus 18 waar Jethro advies gee aan sy skoonseun Moses:

.Jy kan dit nie alleen doen nie. Kies jy uit die hele volk bekwame manne wat God vrees, betroubare manne wat onregverdige wins haat. En stel dié aan oor hulle: owerstes wor duisend, owerstes oor honderd, owerstes oor vyftig, owerstes oor tien.

En laat hulle voortdurend oor die volk regspraak uitoefen: al die groot sake moet hulle na jou hring. maar in al dir klein sake moet hulle self regspreek."

Hier het " die eerste erkenning van die noodsaaklikheid van die behoorlike delegasie van verantwoordelikheid.

Baie moderne skrywers het volumes oor hierdie onderwerp -- dié vall organisasie-struktuur. vasstel van verantwoordelikheid en delegeer van werk - geskrywe. maar in Exodus het u dif eerste rekord van die beginsel.

Ja, ons het aan hestuurskennis baie geërf - van die Cirieke: die erkenning van die waarde van die individu en lan die wetenskaplike metode en van die Romeinse Ryk: die beginsel van desentralisasie van outoriteit en verantwoordelikheid.

Firfenisse van organisasie

Teen $1440 \mathrm{kom}$ die boekdrukkuns en in 1494 publiseer Luca Paciolo in Venesië 'n stelsel van hoekhouding met dub- 
bele inskrywings wat binne 50 jaar daarna reeds in Engeland gebruik word.

Die bankwese met sy stelsel van wissels, skuldbriewe en' hedendaagse tjeks, het ons te danke aan die gebruike van Jode sover terug as 1160 , omdat hulle dikwels voortvlugtend was en nie eiendom kon saamdra nie.

Daar is ons assuransie-wetgewing wat ontwikkel het met voorsorg teen verliese op see uitgeneem deur handelaars in Italië so vroeg as 1194 , en wat moontlik selfs deur die ou Romeine gebruik was.

Daar is ons poswese wat dateer vanaf Lodewyk XI van Frankryk wat die eerste publieke versending van briewe in 1470 gereël het.

Daar is ons spoorweë wat so vroeg as 1602 by koolmyne in Engeland 'n aanvang geneem het, en wel met trokke deur perde getrek.

Daar is ons regswese, gebaseer op die Romeins-Hollandse reg.

'n Faktor wat 'n bepalende invloed sou hê op die kapitalisering van nywerheids- en sake-ondernemings in Suid-Afrika en elders is die ontwikkeling van 'n maatskappystruktuur, wat direk aan ons corgedra is vanuit Holland.

Waar ondernemerskapitaal aanvanklik voorsien is deur een persoon en later deur hom en familielede in vennootskap, het dit in die Romeinse Reg al gebruiklik geword, deur die anonieme vennootskap, dat die sakeman self volle verantwoordelikheid neem, terwyl die anspreeklikheid van vennote beperk bly net tot daardie bedrag wat hulle belê het.

Maar met die groot oorsese ontdekkings was hierdie metode nie meer voldoende om alle risikokapitaal te voorsien nie, en die Verenigde Oos-Indiese Kompanjie is die eerste maatskappy aan die Romeins-Hollandsc Reg bekend waar die heginsel van heperkte aanspreeklikheid toegepas is. Hier is naamlik vir die eerste keer in die Oktrooi bepaal dat die Direkteur se persoonlike aanspreeklikheid ook beperk bly tot die bedrag wat hy as kapitaal belê. Die waarde van hierdie beginsel vir die latere kapitaaleisende ondernemings in SuidAfrika en elders kan moeilik oorskat word. 


\section{Die Kaap}

Hierdie selfde Verenigde Oos-Indiese Kompanjie sou grotendeels ons lot bepaal. Trouens, die Hollanders was bestem om die stigters van die Kaap te wees, omdat hulle die handelsvolk van die $17 \mathrm{e}$ en $18 \mathrm{e}$ eeue was. Hulle was 'n klein volkie met onbeperkte ywer, handelsvernuf en ondernemingsgees.

\section{Monopolie}

Jammer dus dat hulle as toonbeeld van private onderneming juis dié sou wees wat die vryheid van handel aan die Kaap aan bande sou lê deur 'n stelsel van monopolistiese konsessies. Langs dié weg het hulle 'n breuk laat ontstaan tussen die boere en die handelslui.

Weens die stelsel het misbruike van omkopery en selfs bedrog floreer.

Jan van Riebeeck skryf byvoorbeeld aan die Here XVII dat die verbruik van linne vir servette en tafeldoeke aansienlik is, omdat almal die servette en selfs skottels wegdra met die gedagte dat dit maar net Kompanjieseiendom is.

Hulle invloed oor ons was groot - byna 'n helfte van ons geskiedenis sedert 1652.

En dit is moontlik dat ' $n$ groot deel van ons erfenis van wantroue teenoor of minagting van die handel uit daardie tyd stam.

\section{Tuisnywerhede}

Gedurende die ganse tydperk tussen die val van die Romeinse Ryk en die Industriële Rewolusie was daar weinig verandering in die vervaardigingsprosesse.

Tuisnywerhede was die orde van die dag - so ook aan die Kaap.

Ten spyte van die feit dat die administrasie van die H.O.I.K. enige fabrieksonderneming met argwaan bejeën het, omdat hulle geglo het dat dit skadelik sou wees vir die Kom. panjie se eie fabrieke in Holland, het klein-industrieë reeds in verskeie vorms ontstaan, en onder die Maleise slawe was daar 'n groot aantal meubelmakers wat nie net vir hulle meesters nie maar ook vir ander meubels gemaak het. 
Silwersmede was ook in die haap werksaam van Van Riebeeck se tyd af, en in 1715 was daar reeds in gilde van silwersmede aan die Kaap.

\section{Industriële rewolusie}

Maar die einde van die tuisnywerheid het aangebreek toe James Watt op 8 Maart 1776 sy stoomgedrewe pomp aan die wêreld getoon het.

Tuisnywerheid en eenvoudige vervaardiging was censklaps verouderd, asook metodes van vervaardiging waarvan haie so oud soos die Midde-Ooste was. Spierkrag is vervang deur masjienkrag -..- die Industriële Rewolusie het begin -.. en daarmee die moderne fabriek.

\section{Merbantilisme}

Hoewel Engeland kort daarna reeds die Kaap oorgeneem het, het die nywerheidsrewolusie nie onmiddellik tot die Канр oorgewaai nie. Trouens, die Britse koloniale regering het in die tydperk van sogenaamde Britse Merkantilisme verkies dat die kolonies die moederland met voedselware en grondstowwe moes voorsien in ruil vir verwerkte produktc.

Brittanje het egter aan andere masjiene begin verkoop en kopers begin finansier. Teen 1830 het België reeds industriële sentrums gehad, maar Frankryk, Duitsland en Italië nog nie. Engeland was los voor. In 1830 reeds kon lord Macaulay in dic Britse Parlement sê: "Our houses are filled with conveniences which the kings of former times might have envied".

Suid-Afrika sou egter nog moes wag tot 1910 voor sy eie fabrieksperiode sou a anbreek. Van 1806 tot 1869 kan beskou word as die landbouperiode, van 1870 tot 1909 as die mynbouperiode en eers daarna volg die nywerheidsperiode, d.w.s. na Uniewording.

Tog was daar reeds voor 1910 tekens van gestadige groei.

Silwersmede Ackermann, Andries Burger en later die beroemde Lötter-familie was aan die Kaap besig.

Die drukkersbedryf is reeds deur 'n Duitser, Juhan Christian Ritter, in 1784 by ons gevestig en hy het selfs Riks. daalders vir die Kompanjie gedruk.

Brandewynstokery, wat reeds in 1672 al aangedurf is, is 
vroeg in die 18e eeu op kommersiële skaal deur Carl Georg Wieser in Stellenbosch beoefen.

Wamakery, die voorloper van vandag se motorfabrieke, is ook vroeg op beperkte skaal beoefen, naar die eerste wamaker op industriële skaal was G. P. Naudé van Stellenbosch, wat in 1816 sy eie ontwerp op die pad geplaas het.

Later het die firma Retief, de Ville en Kie. in die Paarl ontstaan en tot die grootste wamakery in die land gegroei.

Meubelmakery op fabriekskaal is in 1873 in Kaapstad begin deur D. Isaacs en Richard Rothkugel. Vir jare lank was hulle die grontste fabriek in die Kaapkolonie met 'n personeel van 300 .

Suikerproduksie is in 1820 reeds ondersoek deur Nathaniel Isaacs, later bevorder deur Bergtheil (wat die katoenpionier van Natal was) en baie verder gevoer deur Daniel de Pass.

Alois Nellmapius was na regte 'n voorganger van Marks en Lewis: hy het van president Burgers die reg verkry om 'n roete na Lourenco Marques oop te sit en hy het 'n reeks depots opgerig van Pretoria af na die Portugese gebied. Sy depot by Eerste Fabrieke het meer as net 'n depot en winkel geword en toe Marks en Lewis aldaar begin het met baksteenen teëlvervaardiging, brouery en stokery, vrugte- en vleispreservering, konfytfabriek, sowel as looiery en skoenmakery, was hy saam met hulle daarin betrokke.

Tabakverwerking en -vervaardiging is die eerste keer op kommersiële en industriële wyse gedoen deur L. Rubin en M. Pevsner, in opvolging van pionierswerk deur Herman en Canard.

Die eerste klerefabriek is in 1907 in Kaapstad gestig en het gestaan onder die name van Reuben Back, Simon Roy en Bernard Shub.

Hierdie vroeë voorbeelde van industriële pogings toon" hoe 'n wye erfenis van bekwaamhede en ondernemingsgees ons gehad het om die latere ontwikkelings te steun.

\section{Industriële tydperk}

Die tydperk ná Uniewording in 1910 is die tydperk van industrialisasie. 
Tot 1910 het Suid-Afrika goud, diamante en 'n paar plaasprodukte uitgevoer en feitlik alles ingevoer.

Van 1910 tot 1960 was die groei geweldig.

Ek moes twee maal referate hou oor die onderwerp van Suid-Afrika se nywerheidsgroei - -. naamlik in 1950 voor die Ekonomiese Volkskongres en in 1961 voor die hoofde van die wêreldbeurse in Johannesburg, en het beide male grafieke laat trek oor die verskillende aspekte om ons nywerheidsgroei te illustreer.

Beide kere het die grafieke my getref deur hulle fenomenale groeikurwes.

In 1910 was die nywerheidsbydrae tot die nasionale inkomste van Suid-Afrika minder as $E l 0$ miljoen. Vandag is dit meer as 6500 miljoen. In 1910 was die persentasie bydrae van die privaatnywerheid tot die nasionale inkomste $1 / 15$, vandag is dit meer as $1 / 4$.

Waaraan is hierdie snelle groei toe te skrywe?

\section{Eerste Wêreldoorlog}

Die eerste stoot vorentoe was die invoerprobleme gedurende die Eerste Wêreldoorlog, 1914 - 1918.

Ongeveer 1,600 voedsel- en ander klein fabrieke is toe Restig.

\section{Tarlefbeskerming}

Die na-oorlogse probleme het 'n bewindsverandering in 1924 meegebring en in 1925 het die Hertzogregering begin met 'n beleid van tariefbeskerming. Dit gee die tweede groot stoot vorentoe.

Dit was 'n beleid van selektiewe beskerming, maar so effektief dat produksie in die dertien jaar van 1925 tot 19.38 verdubbel het.

In dié tydperk egter val die wêreldwye depressie van 1929 tot 1932 wat allerernstige probleme meegebring het. Op een stadium was daar 'n 300,000 blanke armes in Suid-Afrika.

$\mathrm{Na}$ Suid-Afrika afgestap het van die goudstandaard en pariteit met die Britse pond in Desember 1932 herstel is, het ons nooit weer teruggekyk nie. 
Goudprys slyg

Die prys van goud het van $85 /$ - na 125 /- per ons gestyg. In 1934 het die V.S.A. self gedevalueer en die prys van goud op $\$ 35$ per ons gestel. Gelyktydige geldkoersverandering het die goudprys tot $142 /-$ per ons gebring.

Hierdie stygings in goudprys was dus die derde groot stoot. Die myne en die nywerheid het floreer. YSKOR het in 1934 met staalproduksie begin en die groot nywerheidsvordering het die armblanke probleem stadig opgelos, deurdat die beskermingsbeleid die stigting van verpakkings- en monteerfabrieke meegebring het.

\section{Thueede Wêreldoorlog}

Die vierde groot stoot vorentoe was die tekorte meegebring deur die Tweede Wêreldoorlog. Dit het veral 'n groot groei in die metaal- en ingenieursbedrywe meegebring. Die aantal werknemers in die Suid-Afrikaanse nywerheid het in die ses jaar van 1939 tot 1945 tnegeneem met soveel as in die vorige dertien jaar.

Die na-oorlogse tekorte het die nywerheid steeds gestimuleer, maar uitermatige invoere het valutaprobleme meegebring en soos in 1925 het die Nasionale regering weer 'n stimulus aan die nywerheid gebring -... hierdie keer deur invoerbeheer.

Toe Suid-Afrika in September 1949 sy geldeenheid saam met $n$ reeks ander lande gedevalueer het, is die goudprys na 250/- per ons opgestoot en dit het verdere nywerheidsgroei aangemoedig.

Van 194.5 tot 1955 het die aantal arbeiders in die nywerheid weereens verdubbel.

Waar die nywerhede voor die oorlog veeleer monteer- en herverpakkingsbedrywe was. is hulle nou veel meer werklike vervaardigingsbedrywe.

In 1950 het ek in ' $n$ referaat oor die nywerheid voor die kkonomiese Volkskongres die volgende gesê: ..Ons praat so dikwels van Suid-Afrika se nywerheidsvordering. maar min van ons besef dat ons gedurende die afgelope vyf-en-twintig jaar 'n nywerheidsrewolusie beleef het. Ons het waarskynlik op nywerheidsgebied vinniger gevorder as enige ander land in die wêreld - self vinniger as Amerika of Rusland". 
Sedert daardie tyd - 1950 - het ons nywerheidsproduksie alrceds weer verdubbel.

Gevolge

En wat was die gevolge van hierdie nywerheidsontwikkeling?

$\mathrm{O}_{\mathrm{p}}$ die Ekonomicse Volkskongres dertien jaar gelede dit was vòòr Nkrumah nog sy party gestig het - het ek my soos volg hieroor uitgelaat:

„Ons het gedurende die afgelope 25 jaar 'n nywerheidsland geword. Dit het gebeur onder omstandighede van selfbehoud. Dit het gekom van hierdie nasionale strewe van die Afrikaner. Dit het die lewenspeil verhoog. Dit het werk verskaf aan duisende Afrikaners, sodat ons vandag reeds 'n halfmiljoen in die stede tel.

„Maar dit het ook werkverskaffing gebring aan honderdduisende naturelle. Die ongekende groei het meer as 30,000 naturelle per jaar na die stede gelok en meer naturelle uit die Noorde na Suid-Afrika getrek as ooit gedurende die vorige eeu. Daar is vandag ruim 'n halfmiljoen vreemde naturelle in die Unie.

„Dit is 'n Christelike prestasie dat ons in teenstelling met bv. Australië en die Verenigde State van Amerika, nie die inheemse bevolking verdelg het nie. Inteendeel, toe ons die naturel op sy trek na die Suide onder die druk van slawehandelaars ontmoet het, het ons hom beskerm. Ten spyte van ander opvattings is dit deur ons toedoen, ons tegniese vaardigheid, dat die naturel kon hestaan, kon aanwas. Daarom is daar steeds die drang by naturelle van ander gebiede na ons.

„Hierdie ontwikkelings het egter een van ons grootste akiuele vraagstukke meegebring. Elke stad in die Unie het tans meer nie-blanke inwoners as blankes, en aan naturellebehuising alleen word volgens $\mathrm{dr}$. Language se berekening 'n $£ 100$ miljoen benodig. Vir die vreemde nyweraar wat slegs wil eksploiteer blyk dit geen probleem nie. Die Afrikaanse nyweraar wat in volksverband staan voel egter bekommerd.

„Stel u daarenteen voor wat sal gebeur as ons ons moet onttrek. Stel usclf die chaos voor. Vir die bestaan van beide is dit nodig dat ons ons meesterskap moet handhaaf, maar 'n 
meesterskap wat teer op prestasie. Meester wees maar Meester werd.

„Laat ons dus ons beskawingstaak aanvaar. Ons moet ons nywerhede nog verder uitbou sodat ons finansieel in staat sal wees om reg te laat geskied en om te kan bestaan as goudontginning eendag verval.

„Ons moet ons staal- en petrolnywerhede uitbou om beide ons en die naturel te beskerm teen ' $n$ vreemde juk in geval van 'n nuwe oorlog. Daar moet naturelle wees wat weet dat ons howe die basiese menslike regte beskerm, en ook sal twyfel an die voorgegewe vryheid uit vreemde lande.

„Ons het verder die plig om die naturel te help om sy tuisnywerhede te ontwikkel en ook sy bestaan te verseker.

„Ekonomiese redes het die naturel uit sy gebiede gebring. Alleen ekonomiese redes kan hom daar hou.

„In dié verband sou ek graag twee gedagtes in u midde wou lê.

„Eerstens, dat ons Afrikaanse nyweraars dit op hulle sal neem om 'n maatskappy sonder winsbejag te stig - sê die Bantoe Ontwikkelingskorporasie - met 'n aanvangskapitaal van 'n $£ 5,000$ wat deur die Afrikaner voorgeskiet moet word, met die oog daarop om lokale nywerhede in die naturellegebiede op beskeie manier aan te voor. Dit moet dien as blyk van ons goeie bedoelings en opregte strewe.

„Tweedens, moet ons hand aan hand hiermee in Korporasie daarstel vir immigrasie uit Europese lande. Ons het reeds 'n tekort aan geskoolde blanke arbeid, selfs ook, meen ek, op ons plase. Ons moet hierdie twee hand aan hand laat gaan -- die een moet die ander aanvul."

Ongelukkig is die idee van so in ontwikkelingskorporasie, wat my Groep in die buiteland verwerk het tot nywerheidsvennootskap selfs ook met die ontwikkelendes - in Maleia en in Jamaika - hier nooit toegepas nie.

Dit is naamlik teen die staatsbeleid. Hulle sê naamlik dat ons blankes die naturelle sal uitbuit.

Hier het ons dan weer die spore van die geskiedenis.

Eerstens, soos die Verenigde Oos-Indiese Kompanjie, glo die staat daaraan dat net ,amptenare" in staat is om as eerlike ondernemers op te tree.

Tweedens, soos Brittanje in sy merkantilistiese periode, 
glo sommige nog dat ons die nywerheidsprodukte moet lewer in ruil vir rouprodukte uit die Bantoegebiede.

Dit is ' $\mathrm{n}$ verouderde denke. Die beste bewys dat handel veeleer geword het die uitruil van produkte tussen hoogs geïndustrialiseerde lande, is te vind in Engeland se pogings om aan te sluit by die Europese Gemeenskapsmark.

Laat hulle tog nie vir $u$ vertel dat as daar fabrieke in die Bantoegebiede is, ons fabrieke sal moet sluit nie.

Inteendeel, ons ken sulke bangmaakstories goed. In die dertiger jare is daar 'n magtige kampanje gevoer teen die koms van ons eie staalwerke, want as YSKOR nie bankrot sou speel nie, sou hy dan kamtig daartoe bydra dat ons nie meer van Engcland kon koop nie en hy nie van ons nie. Ons landbouprodukte sou lê en vrot, so is gesê.

Maar die antwoord was die teendeel. Ons het so baie gekoop dat ons invoerbeheer moes toepas. Ons koop wel nie meer sinkplate of spoorstawe nie, maar nou elektroniese materiaal.

Ons hoef nie bang te wees om ander te ontwikkel wanneer ons weet dat helfte van die produkte wat vandag gemaak word, vyf-en-twintig jaar gelede onbekend was!

Ek kom van een van ons oudste Kaaplandse dorpe, waar ek in my eerste jare geen pypgeleide binnenshuise water, geen afloopbad, geen elektriese lig geken het nie. Daar was geen radio, geen gehoortoestelle, geen radar, geen spuitvliegtuie, geen diesel, geen balpuntpen, geen selfopwenhorlosie, geen flitskamera, geen bandopnamemasjien, ja, selfs nie papiersakdoeke nie.

En vyf-en-twintig jaar van nou af sal $u$ weer so kan praat.

\section{Skaduwee van Castro}

Die Weste is op die verdediging. Met net een vurige tclevisietoespraak het Castro $\$ 1$ biljoen Amerikaanse beleggings uitgewis. Die swaard van ekspropriasie hang oor 'n verdere $\$ 8$ miljoen aan Amerikaanse beleggings in daardie Suiderkontinent. In 1957 was die vloei van Amerikaanse beleggings na Suid-Amerika nog $\$ 1.5$ biljoen. In die eerste ses maande van 1962 was dit 'n ronde nul. 
Die skaduwee van Castro hang oor 'n kontinent. Die harde, byna ondraaglike, ekonomiese kondisies tesame met buitensporige inflasie, het die kapitalistiese organisasie in party dele van Latyns-Amerika tot op die rand van die afgrond gestoot. Die minderbevoorregte en die jong intelektuele is reeds geneig tot Kommunisme as 'n aanvaarbare antwoord.

Die huiseienaarskap is van die laagste in die wêreld, want daar is byna geen bougenootskap of soortgelyke organisasie nie. Van die 30 miljoen huise is tweederdes ongeskik. Daarbenewens is 70 miljoen of $40 \%$ van die bevolking onder 15 jaar oud. Sonder vervanging benodig hulle 'n miljoen huise per jaar, en daar is geen Westerse finansiële organisasie om dit moontlik te maak nie.

Die sleutel tot die onderontwikkeling van Latyns-Amerika is die ongebruikte kapasiteit van byna die hele area aangesien die grootste gedeelte van die menslike, natuurlike en kapitaalbronne van die gebied ongebruik is.

Waar lê die antwoord? Ek glo dit lê in ontwikkeling deur nywerheidsvennootskap.

Ons het deur 'n beleid van nywerheidsvennootskap 'n einde gebring aan die konsep van finansiële kolonialisme deur minstens die helfte van die aandele in ons groep se maatskappye, in elke land waar ons fabrieke bou, aan die inwoners van sulke lande te laat toekom, en honderd-duisende daardeur bevoordeel.

Amerika het sedert 1945 meer as 30 biljoen dollar weggegee aan hulp aan onderontwikkelde lande en dit nog nie geleer nie. Sal $\mathrm{u}$ ?

$U$ staan op die drumpel van $u$ lewe in 'n eeu van „WELVAART'!

„Welvaart" bring verantwoordelikhede - dit bring vordering of verval.

As welvaart lei tot losbandigheid en afwys van verantwoordelikheid, is dit 'n vloek.

As welvaart lei tot weldoen aan andere, en dus verryking van die geestelike self, is dit 'n goddelike bate.

As welvaart lei tot die miskenning van die bronne van ons geesteskrag, is dit 'n gevaar. 
Maar welvaart wat lei tot mededeelsaamheid, is u grootste wapen teen Kommunisme.

Die idee is magtiger as die swaard. Jal ons dan nie Kommunisme met hierdie idee van mededeelsaamheid --- dié van nywerheidsvennootskap - beveg nie? Dit, meen ek, is u taak. Daarin lê u redding.

Stellenbosch.

A. E. Rupert. 